\title{
Erratum to: The impact of diabetic retinopathy on quality of life: qualitative findings from an item bank development project
}

Eva K. Fenwick • Konrad Pesudovs •

Jyoti Khadka • Mohamed Dirani · Gwyn Rees •

Tien Y. Wong $\cdot$ Ecosse L. Lamoureux

Published online: 31 March 2012

(C) Springer Science+Business Media B.V. 2012

\section{Erratum to: Qual Life Res}

DOI 10.1007/s11136-012-0110-1

The Acknowledgments section in the original publication was incorrect. The correct text is as follows:

Acknowledgments National Health and Medical Research Council Centre for Clinical Research Excellence (CCRE)
\#529923-Translational Clinical Research in Major Eye Diseases; CCRE Diabetes; Novartis Pharmaceuticals Australia \#CRFB002DAU09T; Royal Victorian Eye and Ear Hospital; Operational Infrastructure Support from the Victorian Government.

The online version of the original article can be found under doi:10.1007/s11136-012-0110-1.

E. K. Fenwick · M. Dirani - G. Rees · T. Y. Wong ·

E. L. Lamoureux $(\square)$

Centre for Eye Research Australia, Royal Victorian Eye and Ear

Hospital, University of Melbourne, 32 Gisborne St,

East Melbourne, VIC 3002, Australia

e-mail: ecosse@unimelb.edu.au

K. Pesudovs $\cdot$ J. Khadka

Discipline of Optometry and Vision Science, NH\&MRC Centre

for Clinical Eye Research, Flinders University and Flinders

Medical Centre-Australia, Adelaide, Australia

T. Y. Wong · E. L. Lamoureux

Singapore National Eye Centre, Singapore Eye Research

Institute, Singapore, Singapore 